\title{
BAIBA attenuates insulin resistance and inflammation induced by palmitate or a high fat diet via an AMPK-PPAR $\delta$-dependent pathway in mice
}

\author{
Tae Woo Jung ${ }^{1}$ Hwan-Jin Hwang ${ }^{1}$ Ho Cheol Hong ${ }^{1} \cdot$ Hye Jin Yoo ${ }^{1} \cdot$ Sei Hyun Baik ${ }^{1}$. \\ Kyung Mook Choi ${ }^{1}$
}

Received: 4 February 2015 / Accepted: 21 May 2015 /Published online: 24 June 2015

(C) Springer-Verlag Berlin Heidelberg 2015

\begin{abstract}
Aims/hypothesis We explored the effects of $\beta$-aminoisobutyric acid (BAIBA) on hyperlipidaemic-condition-induced insulin resistance and inflammation as mediated through a signalling pathway involving AMP-activated protein kinase (AMPK) and peroxisome proliferator-activated receptor $\delta$ (PPAR $\delta$ ).

Methods Mouse skeletal muscle $\mathrm{C} 2 \mathrm{C} 12$ cells and C57BL/6J mice were treated with palmitate or a high-fat diet (HFD) and BAIBA. Inflammation and the expression of genes associated with insulin signalling were determined by western blot and quantitative real-time PCR. Selected genes from candidate pathways were evaluated by small interfering (si)RNA knockdown and specific inhibitors.

Results BAIBA treatment ameliorated impairment of insulin receptor substrate (IRS)-1/Akt-mediated insulin signalling in palmitate-treated $\mathrm{C} 2 \mathrm{C} 12$ myocytes and in skeletal muscle of HFD-fed mice. In addition, BAIBA treatment reversed HFDinduced increases in body weight and improved impaired glucose tolerance in mice. In vitro and in vivo, inhibitory $\mathrm{kB} \alpha$ $(\mathrm{I} \kappa \mathrm{B} \alpha)$ phosphorylation, nuclear factor $\mathrm{\kappa B}(\mathrm{NF} \kappa \mathrm{B})$ nuclear translocation and downstream inflammatory cytokines were significantly suppressed by BAIBA. Furthermore, BAIBA treatment significantly induced AMPK phosphorylation and expression of PPAR $\delta$ in $\mathrm{C} 2 \mathrm{C} 12$ myocytes and in skeletal muscle of mice. Both compound C, an AMPK inhibitor, and Ppar $\delta$ (also known
\end{abstract}

Kyung Mook Choi

medica7@gmail.com

1 Division of Endocrinology and Metabolism, Department of Internal Medicine, Korea University Guro Hospital, 80 Guro-Dong,

Guro-Gu, Seoul 152-050, Republic of Korea as Ppard) siRNA abrogated the inhibitory effects of BAIBA on palmitate-induced inflammation and insulin resistance. BAIBA significantly induced the expression of genes associated with fatty acid oxidation, such as carnitine palmitoyltransferase 1 (Cpt1), acyl-CoA oxidase (Aco; also known as Acoxl) and fatty acid binding protein 3 (Fabp3); this effect of BAIBA was significantly reduced by compound $\mathrm{C}$ and Ppar $\delta$ siRNA.

Conclusions/interpretation These results are the first to demonstrate that BAIBA attenuates insulin resistance, suppresses inflammation and induces fatty acid oxidation via the AMPKPPAR $\delta$ pathway in skeletal muscle.

Keywords AMP-activated protein kinase · Inflammation · Insulin resistance $\cdot \beta$-Aminoisobutyric acid

$\begin{array}{ll}\text { Abbreviation } \\ \text { AMPK } & \text { AMP-activated protein kinase } \\ \text { BAIBA } & \beta \text {-Aminoisobutyric acid } \\ \text { DMEM } & \text { Dulbecco's modified eagle medium } \\ \text { HFD } & \text { High-fat diet } \\ \text { IPGTT } & \text { Intraperitoneal glucose tolerance test } \\ \text { IRS-1 } & \text { Insulin receptor substrate-1 } \\ \text { ITT } & \text { Insulin tolerance test } \\ \text { MCP-1 } & \text { Monocyte chemotactic factor-1 } \\ \text { ND } & \text { Normal diet } \\ \text { NFkB } & \text { Nuclear factor } \kappa \text { B } \\ \text { IkB } \alpha & \text { Inhibitory } \kappa \text { B } \alpha \\ \text { PGC-1 } \alpha & \text { Peroxisome proliferator-activated } \\ \text { PPAR } \delta & \text { receptor-gamma coactivator-1 } \alpha \\ \text { siRNA } & \text { Small interfering RNA }\end{array}$




\section{Introduction}

Although regular exercise increases insulin sensitivity in humans [1], the underlying mechanisms are not completely understood. Begriche et al demonstrated that $\beta$ aminoisobutyric acid (BAIBA), a natural catabolite of thymine, reduced body fat percentage through increased fatty acid oxidation and decreased de novo lipogenesis in mice [2]. Recently, Roberts et al identified BAIBA as a small molecule myokine secreted from myocytes with forced expression of peroxisome proliferator-activated receptor-gamma coactivator- $1 \alpha(\mathrm{PGC}-1 \alpha)$. BAIBA enhances the browning of white adipose tissue and $\beta$-oxidation in the liver through a mechanism mediated by peroxisome proliferator-activated receptor $\alpha(\operatorname{PPAR} \alpha)[3]$.

Elevated plasma NEFA levels are observed in individuals with insulin resistance [4]. In particular, saturated NEFA has been reported to induce insulin resistance [5]. Moreover, elevated levels of saturated NEFA induce inflammation, which results in insulin resistance via several pathways involving diacylglycerol-mediated protein kinase $\mathrm{C}$ activation [6] or Toll-like receptors [7]. These pathways lead to activation of nuclear factor- $\mathrm{kB}(\mathrm{NF} \mathrm{KB})$, a proinflammatory transcription factor, which impairs insulin signalling in skeletal muscle [8]. Under inflammatory conditions, NFKB induces the expression of various proinflammatory cytokines, such as TNF- $\alpha$ and IL-6, which are associated with insulin resistance and type 2 diabetes [9].

The current study investigated the influence of the novel myokine BAIBA, which exerts ameliorating effects on inflammation and insulin resistance. Furthermore, to elucidate the cellular mechanisms through which BAIBA influences inflammation and insulin resistance, we explored a downstream signal transduction pathway involving AMPactivated protein kinase (AMPK) and PPAR $\delta$ in $\mathrm{C} 2 \mathrm{C} 12$ myocytes and in mouse skeletal muscle.

\section{Methods}

Cell cultures, reagents and antibodies The mouse skeletal muscle cell line C2C12 (ATCC, Manassas, VA, USA) was cultured in Dulbecco's modified eagle medium (DMEM) (Invitrogen, Carlsbad, CA, USA) supplemented with 10\% fetal bovine serum (Invitrogen), 100 units $\mathrm{ml}^{-1}$ penicillin and $100 \mu \mathrm{g} \mathrm{ml}^{-1}$ streptomycin (Invitrogen). Cells were incubated in a humidified atmosphere of $5 \% \mathrm{CO}_{2}$ at $37^{\circ} \mathrm{C}$. Cells were supplemented with $2 \%$ horse serum to induce differentiation. Mycoplasma contamination was not detected in $\mathrm{C} 2 \mathrm{C} 12$ cells. BAIBA (Sigma, St Louis, MO, USA) was dissolved in distilled water. Compound C (Sigma) was dissolved in DMSO and added to the culture medium. Sodium palmitate (Sigma) was conjugated to $2 \%$ BSA (fatty acid free; Sigma) dissolved in DMEM. The final concentration of DMSO did not exceed $0.1 \%$, which did not affect cell viability. In all experiments, cells were treated with palmitate-BSA for $24 \mathrm{~h}$ and $2 \%$ BSA was used as a control. Anti-phospho Akt (Ser473; 1:1000), anti-Akt (1:2500), anti-insulin receptor substrate (IRS)-1 (1:2500), anti-phospho AMPK (Thr172; 1:1000), antiAMPK (1:2500), anti-NFkBp65 (1:2500), anti-phospho IкB $\alpha$ (Ser32; 1:1000), anti-IL-6 (1:2500) and anti-PPAR $\delta(1: 2500)$ antibodies were purchased from Cell Signaling (Beverly, MA, USA). Anti-phospho IRS-1 (Tyr 632; 1:1000) and anti-betaactin (1:5000) antibodies were purchased from Santa Cruz Biotechnology (Santa Cruz, CA, USA).

Animals, feeding, treatment, in vivo insulin signalling, intraperitoneal glucose tolerance test and insulin tolerance test This study was approved by the institutional animal review board (Institutional Animal Care and Use Committee) of Korea University, Seoul, Korea. A control group and two experimental groups of 8-week-old male C57BL/6J (B6) mice were given a normal diet (ND; $11.92 \mathrm{~kJ} \mathrm{~g}^{-1} ; 12.6 \%$ energy from fat, $26.7 \%$ from protein and $60.7 \%$ from carbohydrate; Brogaarden, Gentofte, Denmark) and a high-fat diet (HFD; $21.92 \mathrm{~kJ} \mathrm{~g}^{-1} ; 60 \%$ energy from fat, $20 \%$ from protein and $20 \%$ from carbohydrate; Research Diets, New Brunswick, NJ, USA), respectively, for 8 weeks. The HFD-BAIBA group received $150 \mathrm{mg} \mathrm{kg}^{-1}$ day $^{-1}$ of BAIBA dissolved in drinking water given ad libitum for 8 weeks. Soleus muscle samples were harvested $10 \mathrm{~min}$ after mice were given an intraperitoneal injection of human insulin (Novo Nordisk, Princeton, NJ, USA; $10 \mathrm{U} \mathrm{kg}^{-1}$ body weight). For the intraperitoneal glucose tolerance test (IPGTT), mice fasted for overnight $(12 \mathrm{~h}$ ) were given an intraperitoneal injection of glucose $\left(2 \mathrm{~g} \mathrm{~kg}^{-1}\right.$ body weight). Blood samples were harvested from the tail vein before glucose challenge, as well as 30,60, 90 and $120 \mathrm{~min}$ thereafter. For the insulin tolerance test (ITT), mice fasted for $6 \mathrm{~h}$ were given an intraperitoneal injection of human insulin $\left(1 \mathrm{U} \mathrm{kg}^{-1}\right.$ body weight $)$. Blood samples were harvested from the tail vein before glucose challenge, as well as 15 , 30, 45 and 60 min thereafter. Serum glucose levels were measured using Accu-Chek III glucose analyser. After an 8 week study period, mice of all groups were killed under anaesthesia after fasting overnight $(12 \mathrm{~h})$.

RNA isolation and quantitative real-time PCR Each complementary DNA (cDNA) sample was analysed for gene expression by quantitative real-time PCR using the fluorescent TaqMan 5'-nuclease assay on an Applied Biosystems 7000 sequence detection system (Foster City, CA, USA). The TaqMan real-time PCR was performed using $2 \times$ TaqMan Master Mix and the 20× premade TaqMan gene expression assays (Applied Biosystems). The following PCR conditions were used: $95^{\circ} \mathrm{C}$ for $10 \mathrm{~min}, 95^{\circ} \mathrm{C}$ for $15 \mathrm{~s}$ and $60^{\circ} \mathrm{C}$ for $1 \mathrm{~min}$ for 45 cycles. The levels of expression of mouse carnitine 
palmitoyltransferase 1 (Cpt1) (Mm00463960_m1; Applied Biosystems), acyl-CoA oxidase (Aco) (Mm00801417 m1) and fatty acid binding protein 3 (Fabp3; Mm02342495_m1) messenger RNAs (mRNAs) were normalised to mouse betaactin (Mn00607939_sl; Applied Biosystems).

Immunoblotting analysis $\mathrm{C} 2 \mathrm{C} 12$ cells were harvested and proteins were extracted with lysis buffer (PRO-PREP ${ }^{\mathrm{TM}}$; Intron Biotechnology, Seoul, Korea) for $60 \mathrm{~min}$ at $4^{\circ} \mathrm{C}$. Protein samples $(30 \mu \mathrm{g})$ were subjected to $10 \%$ SDS-PAGE, transferred to a nitrocellulose membrane (Amersham Bioscience, Westborough, MA, USA) and probed with primary antibody followed by secondary antibody conjugated with horseradish peroxidase (Amersham Bioscience). The samples were detected with chemiluminescence kits (Amersham Bioscience).

Transfections using siRNAs $0-20 \mathrm{nmol} / \mathrm{l}$ small interfering (si)RNA oligonucleotides for PPARס (SC-36305; Santa
Cruz Biotechnology) were used to suppress gene expression. Transfection was performed with Lipofectamine 2000 (Invitrogen), in accordance with the manufacturer's directions.

Measurement of NFKB nuclear translocation Cells were fractionated using a Nuclear/Cytosol Fractionation Kit, as described in the manufacturer's instructions (Biovision, Milpitas, CA, USA).

Glucose uptake, acetyl-CoA and ATP measurement Glucose uptake levels, intracellular acetyl-CoA and ATP in cells or tissues were measured using assay kits, as described in the manufacturer's directions (Abcam, Cambridge, MA, USA).

Statistical analysis All analyses were performed using the SPSS/PC statistical program (version 12.0 for Windows; SPSS, Chicago, IL, USA). Results are presented as the fold
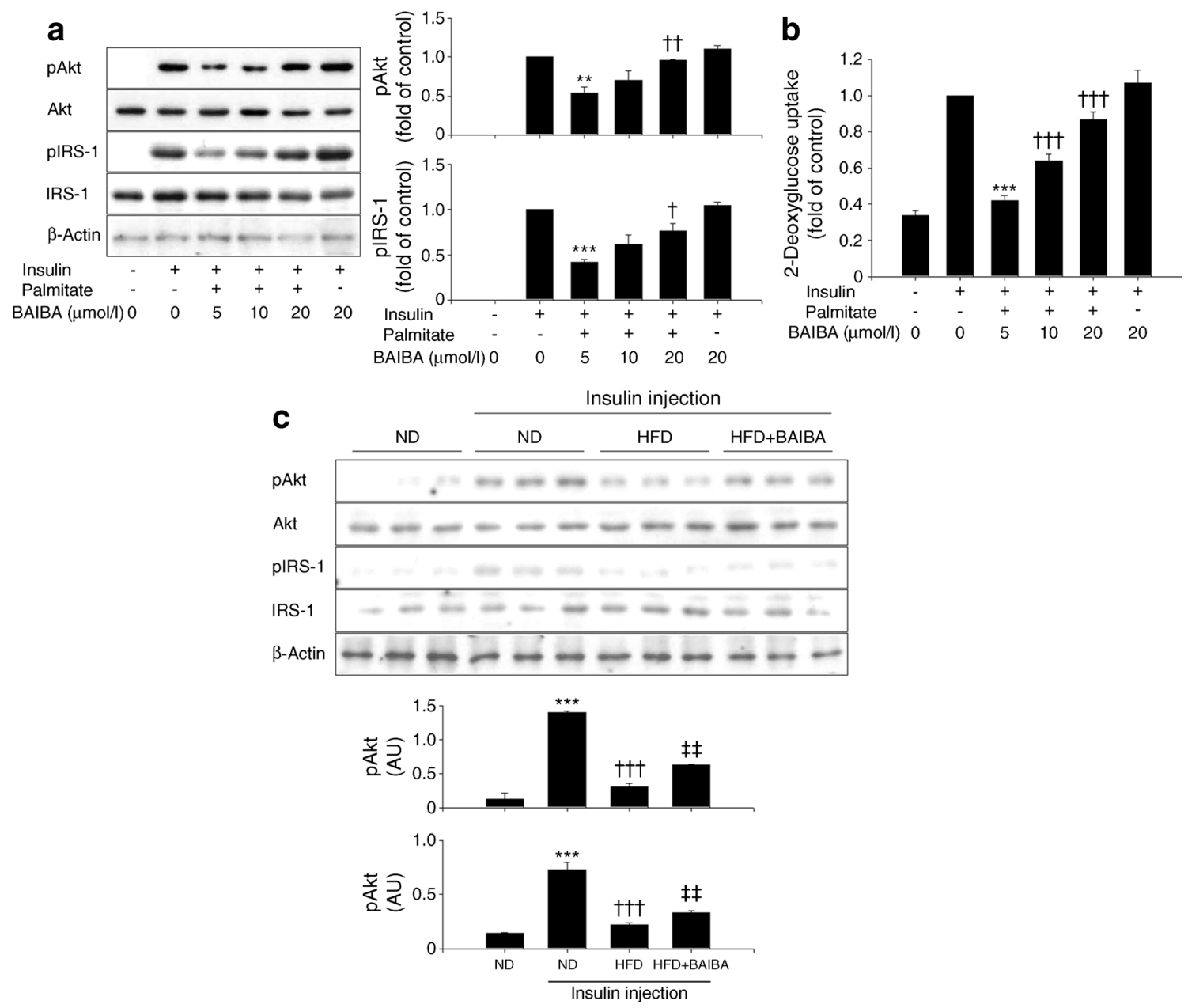

Fig. 1 BAIBA improves insulin resistance in skeletal muscle cells. (a) Western blot analysis of Akt and IRS-1 phosphorylation and (b) 2deoxyglucose uptake in $\mathrm{C} 2 \mathrm{C} 12$ myocytes treated with BAIBA $(0$ $20 \mu \mathrm{mol} / \mathrm{l})$ for 5 days and palmitate $(200 \mu \mathrm{mol} / \mathrm{l})$ for $24 \mathrm{~h}$. Insulin $(10 \mathrm{nmol} / 1)$ was used to stimulate IRS-1 and Akt for $3 \mathrm{~min}$. (c) Western blot analysis of Akt and IRS-1 phosphorylation in soleus skeletal muscle from mice treated with HFD and BAIBA (four animals per treatment group). Data are presented as the mean \pm SEM of three separate experiments. ${ }^{* *} p<0.001$ and ${ }^{* *} p<0.01$ when compared with the control or the ND treatment. ${ }^{\dagger \dagger} p<0.001,{ }^{\dagger \dagger} p<0.01$ and ${ }^{\dagger} p<0.05$ when compared with palmitate or insulin-injected ND treatment. ${ }^{*} p<0.01$ when compared with insulin-injected HFD treatment 
difference relative to control values (mean \pm SEM). All of the in vitro experiments were conducted a minimum of three times. Student's $t$ test or two-way ANOVA were used in the statistical analysis.

\section{Results}

BAIBA treatment prevents hyperlipidaemia-induced insulin resistance in $\mathrm{C2C12}$ myocytes and skeletal muscle of HFD-fed mice To evaluate the effects of BAIBA on palmitate-induced insulin resistance, we examined the effect of BAIBA on the levels of insulin-stimulated Akt and IRS-1 phosphorylation. It has been reported that plasma concentration of BAIBA was $8.9 \pm 0.5 \mu \mathrm{mol} / 1$ in mice treated with $170 \mathrm{mg} \mathrm{kg}^{-1} \mathrm{day}^{-1}$ of BAIBA [3]. Therefore, $\mathrm{C} 2 \mathrm{C} 12$ mouse skeletal muscle cells were treated with $0-20 \mu \mathrm{mol} / 1$ for 5 days. First, $\mathrm{C} 2 \mathrm{C} 12$ mouse skeletal muscle cells treated with palmitate and isolated soleus skeletal muscle from HFD-fed mice showed impaired insulin sensitivity. However, BAIBA treatment significantly reversed these changes both in vitro and in vivo (Fig. 1a-c).

BAIBA ameliorates HFD-induced insulin resistance in mice We next examined the effect of BAIBA on glucose tolerance and insulin sensitivity by performing an IPGTT and ITT. The IPGTT and ITT revealed that the HFD significantly impaired glucose tolerance and increased insulin resistance compared with the ND. However, BAIBA treatment significantly improved HFD-induced glucose tolerance and insulin resistance (Fig. 2a,b). As HFD-induced basal serum glucose levels were suppressed by BAIBA administration (ND: $6.43 \pm$ $0.15 \mathrm{mmol} / \mathrm{l}$; HFD: $9.32 \pm 0.44 \mathrm{mmol} / \mathrm{l}$; HFD+BAIBA: $6.74 \pm$ $0.29 \mathrm{mmol} / \mathrm{l})$, it was difficult to evaluate the ITT results. Therefore, we used a graph in \% of basal glycaemia to estimate the effect of BAIBA on insulin sensitivity (Fig. 2b). Furthermore, BAIBA administration significantly decreased the HFD-induced increase in body weight (Fig. 2c), in agreement with previous reports [3]. However, BAIBA treatment did not affect food intake represented by energy intake (Fig. 2d).

BAIBA alleviates palmitate-induced inflammation in C2C12 cells and soleus skeletal muscle of HFD-fed mice BAIBA ameliorated palmitate-induced I $\mathrm{B} \alpha$ phosphorylation, NF $\kappa B$ nuclear translocation, and the expression of IL-6 (a cytokine positively regulated by NFKB) $[9,10]$ in a dose-dependent manner (Fig. 3a). Furthermore, BAIBA administration resulted in significant suppression of HFD-induced $I \kappa B \alpha$ phosphorylation and $\mathrm{NF} \kappa \mathrm{B}$ nuclear translocation in the soleus skeletal muscle of mice (Fig. 3b,c). Serum TNF- $\alpha$ and monocyte
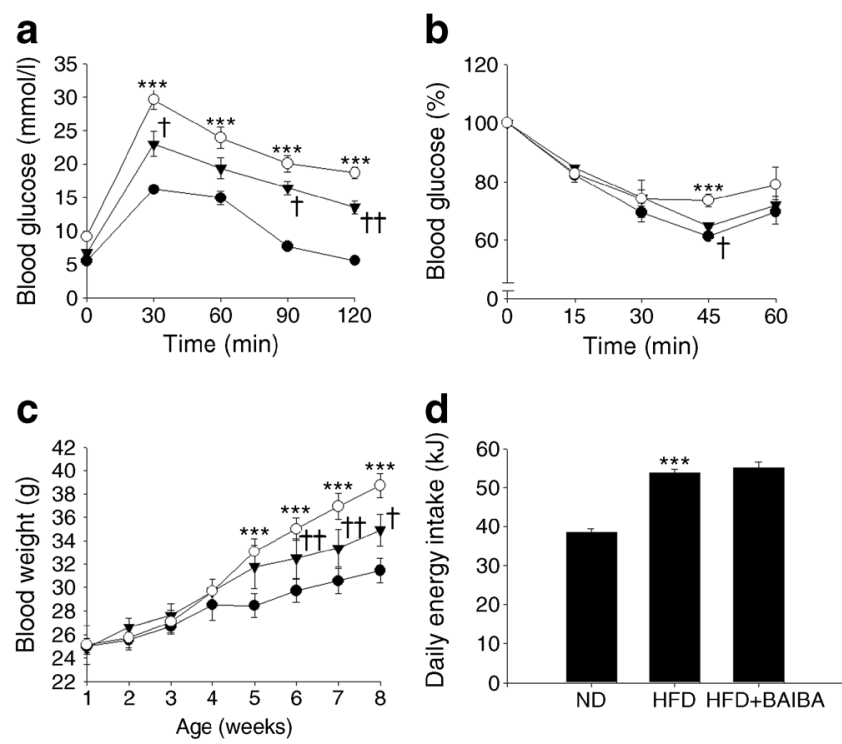

Fig. 2 BAIBA administration improves insulin resistance in mice: (a) IPGTT and (b) ITT. (c) Measurement of body weight and (d) energy intake in mice (seven animals per treatment group). Black circles, ND; white circles, HFD; black triangles, HFD+BAIBA. Mean \pm SEM were calculated from the data obtained from seven separate animals. ${ }^{* * *} p<0.001$ when compared with the ND treatment. ${ }^{\dagger \dagger} p<0.01$ and ${ }^{\dagger} p<0.05$ when compared with the HFD treatment

chemotactic factor-1 (MCP-1) levels were also decreased by BAIBA treatment (Fig. 3d,e).

BAIBA prevents palmitate-induced inflammation, which leads to improvements in insulin resistance through activation of AMPK It has been reported that AMPK is a therapeutic target for treatment of insulin resistance and type 2 diabetes [11]. In the present study, BAIBA induced AMPK phosphorylation in a dose-dependent manner (Fig. 4a). Since the association of inflammation with insulin resistance has been reported [12], we next verified the inhibitory effect of BAIBA on palmitateinduced inflammation through the AMPK-dependent pathway. As shown in Fig. 4b, palmitate increased I $\kappa \mathrm{B} \alpha$ phosphorylation, NF $\kappa \mathrm{B}$ nuclear translocation and IL-6 expression. Notably, the suppressive effects of BAIBA on palmitate-induced inflammation were significantly reversed in the presence of compound $\mathrm{C}$ and Ampk siRNA (Fig. 4b,d). We then evaluated whether BAIBA-induced AMPK contributed to improvements in insulin resistance aggravated by palmitate in $\mathrm{C} 2 \mathrm{C} 12$ myocytes. As shown in Fig. $4 \mathrm{c}$ and e, treatment of C2C12 cells with BAIBA significantly reversed palmitate-induced insulin resistance, as demonstrated by impairment of insulin-stimulated IRS-1 and Akt phosphorylation. The reversible effects of BAIBA on palmitate-induced inflammation and insulin resistance were significantly abolished by both compound $\mathrm{C}$ and 


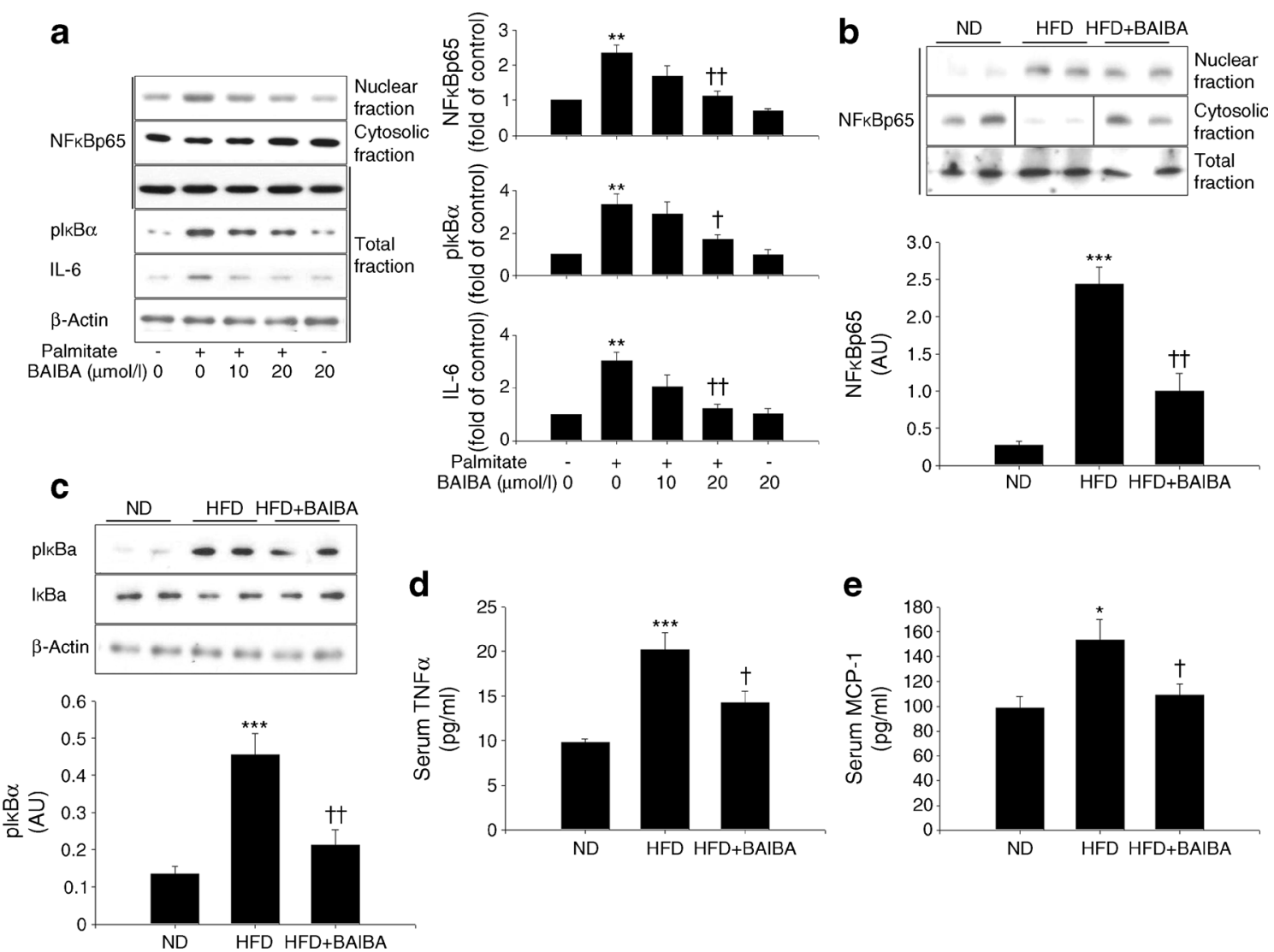

Fig. 3 BAIBA attenuates inflammation in vitro and in vivo. (a) Western blot analysis of palmitate-induced levels of inflammation markers in C2C12 cells treated with BAIBA $(0-20 \mu \mathrm{mol} / \mathrm{l})$ for 5 days. Western blot analysis of HFD-induced (b) NFKB nuclear translocation and (c) IKB $\alpha$ phosphorylation in soleus skeletal muscle of mice treated with HFD and BAIBA (150 mg kg ${ }^{-1}$ day $^{-1}$ ) for 8 weeks. Serum analysis of (d) TNF $\alpha$ and (e) MCP-1 of mice treated with HFD and BAIBA (seven animals per

siRNA for Ampk (Fig. 4c,e). Furthermore, BAIBA administration significantly reversed HFD-suppressed AMPK phosphorylation in the soleus skeletal muscle of mice (Fig. 4f).

The PPAR $\delta$-mediated pathway is involved in the inhibitory effects of BAIBA on palmitate-induced inflammation and insulin resistance Narkar et al reported that AMPK activates genes associated with $\beta$-oxidation via PPAR $\delta$ [13]. PPAR $\delta$ and its ligand are targets for the treatment of inflammation [14-16] and insulin resistance [17-19]. Thus, we examined whether BAIBA augmented PPAR $\delta$ expression in $\mathrm{C} 2 \mathrm{C} 12$ cells. Treatment of $\mathrm{C} 2 \mathrm{C} 12$ cells with BAIBA induced PPAR $\delta$ expression in a dosedependent manner (Fig. 5a). PPAR $\delta$ expression was effectively suppressed by a Ppar $\delta$ (also known as Ppard) siRNA. The Ppar $\delta$ siRNA significantly abrogated the effect of BAIBA on palmitate-induced inflammation and insulin resistance (Fig. 5b,c), suggesting that BAIBA attenuates palmitate-induced inflammation and treatment group). Mean \pm SEM were calculated from the data obtained from seven separate animals. ${ }^{* * *} p<0.001,{ }^{* *} p<0.01$ and ${ }^{*} p<0.05$ when compared with the control or the ND treatment. ${ }^{\dagger \dagger} p<0.01$ and ${ }^{\dagger} p<0.05$ when compared with the palmitate or the HFD treatment. In (b), as the sample was misloaded, the HFD group in the third position was moved to the second position

insulin resistance via the PPAR $\delta$-mediated pathway. In agreement with the in vitro data, BAIBA administration significantly augmented PPAR $\delta$ expression in soleus skeletal muscle from HFD-fed mice (Fig. 5d). BAIBA independently increased PPAR $\delta$ expression and AMPK phosphorylation (Fig. 5e,f).

BAIBA induces fatty acid oxidation through AMPKmediated pathways in $\mathrm{C2C12}$ myocytes and in skeletal muscle of HFD-fed mice It has been reported that incomplete fatty acid oxidation contributes to skeletal muscle insulin resistance [20]. As AMPK and PPAR $\delta$, as well as BAIBA, have been reported to induce fatty acid oxidation [3, 21, 22], we evaluated whether BAIBA-induced AMPK and PPAR $\delta$ could induce fatty acid oxidation in $\mathrm{C} 2 \mathrm{C} 12$ myocytes. As shown in Fig. 6a and b, inhibition of AMPK by compound $\mathrm{C}$ and suppression of PPAR $\delta$ by siRNA significantly abrogated the inducible effect of BAIBA on genes associated with fatty acid oxidation, such as Cpt1, Aco (also known as Acoxl) and Fabp3 
a

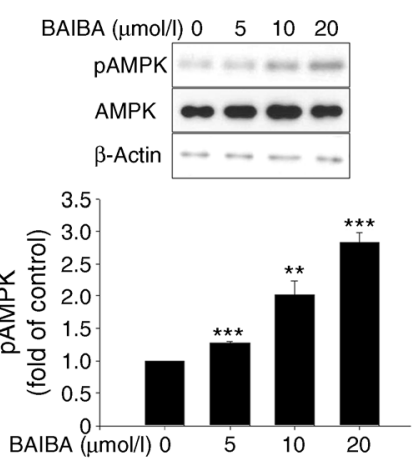

b

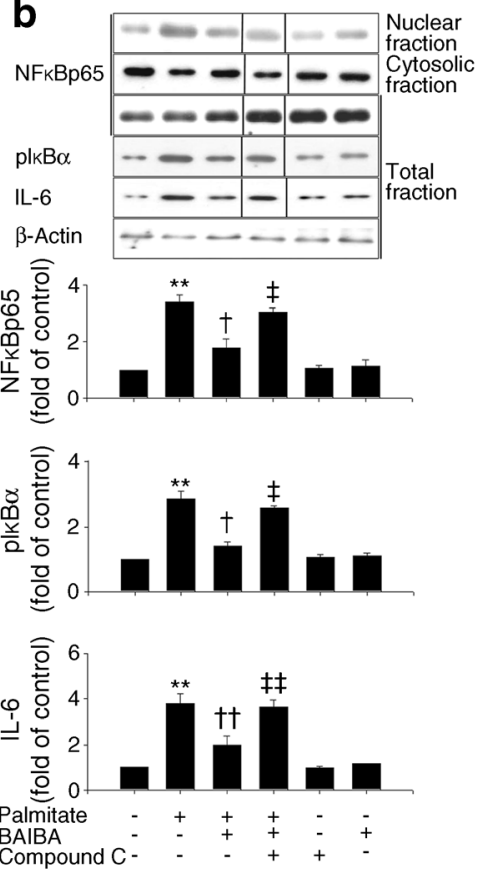

C

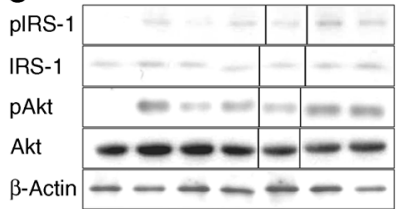

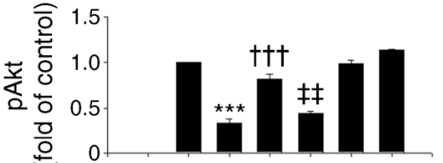

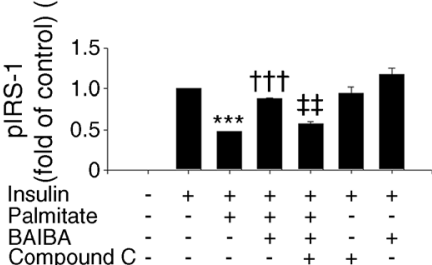

d

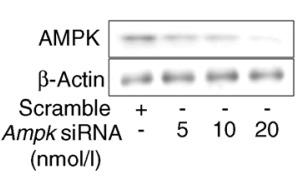

Fig. 4 BAIBA attenuates inflammation and insulin resistance through an AMPK-mediated pathway. (a) Western blot analysis of AMPK phosphorylation in $\mathrm{C} 2 \mathrm{C} 12$ cells treated with BAIBA $(0-20 \mu \mathrm{mol} / \mathrm{l})$ for 5 days. (b) C2C12 cells were treated with BAIBA and compound C $(20 \mu \mathrm{mol} / \mathrm{l}$, $16 \mathrm{~h}$ ). Levels of inflammation markers were determined by western blot analysis. (c) $\mathrm{C} 2 \mathrm{C} 12$ cells were treated with BAIBA and compound $\mathrm{C}$, and western blot analysis of Akt and IRS-1 phosphorylation in $\mathrm{C} 2 \mathrm{C} 12$ cells treated with BAIBA and palmitate $(200 \mu \mathrm{mol} / \mathrm{l})$ for $24 \mathrm{~h}$. (d) Verification of Ampk siRNA efficiency in $\mathrm{C} 2 \mathrm{C} 12$ cells. Western blot analysis of inflammation markers in Ampk siRNA-transfected C2C12 cells treated with BAIBA and palmitate. (e) Ampk siRNA-transfected C2C12 cells were treated with BAIBA and Ampk siRNA, and western blot analysis of
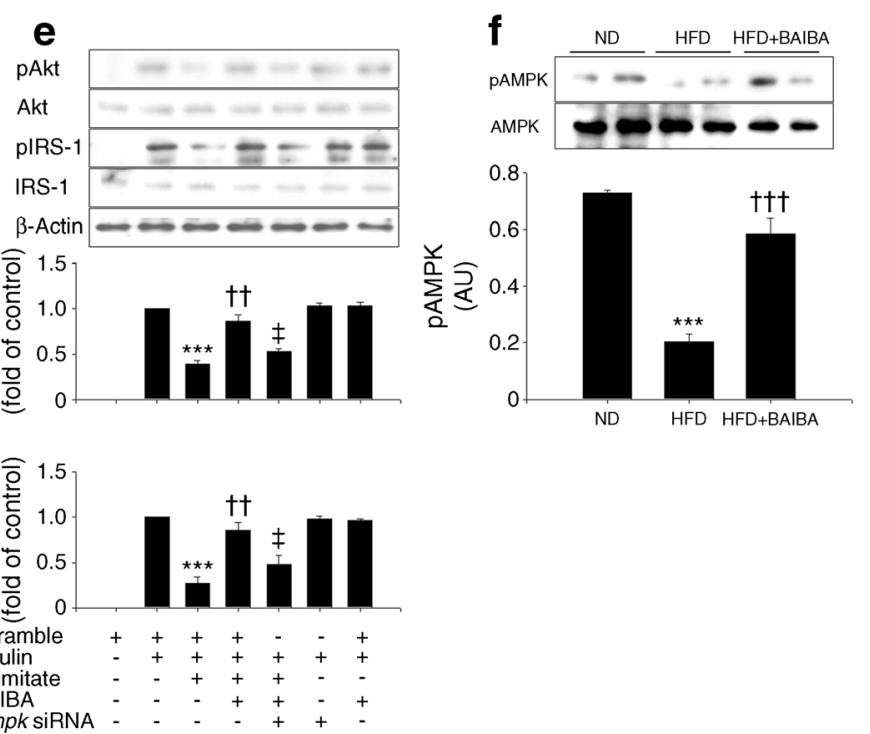

Akt and IRS-1 phosphorylation in $\mathrm{C} 2 \mathrm{C} 12$ cells treated with BAIBA and palmitate. Insulin $(10 \mathrm{nmol} / \mathrm{l})$ was used to stimulate IRS-1 and Akt for $3 \mathrm{~min}$. (f) Western blot analysis of AMPK phosphorylation in soleus skeletal muscle of mice treated with HFD and BAIBA (seven animals per treatment group). Data are presented as the mean \pm SEM of three separate experiments. ${ }^{* * *} p<0.001$ and $* * p<0.01$ when compared with the control or the ND. ${ }^{\dagger \dagger} p<0.001,{ }^{\dagger} p<0.01$ and ${ }^{\dagger} p<0.05$ when compared with the palmitate or the HFD treatment. ${ }^{\star} p<0.01$ and ${ }^{\star} p<0.05$ when compared with the palmitate plus BAIBA treatment or the HFD plus BAIBA treatment. Dividing lines show where splicing has occurred due to exclusion of lanes that were not associated with the current study

Acetyl-CoA and ATP, products of fatty acid oxidation, were also measured. BAIBA administration significantly increased both intracellular acetyl-CoA and ATP (Fig. 6d). 

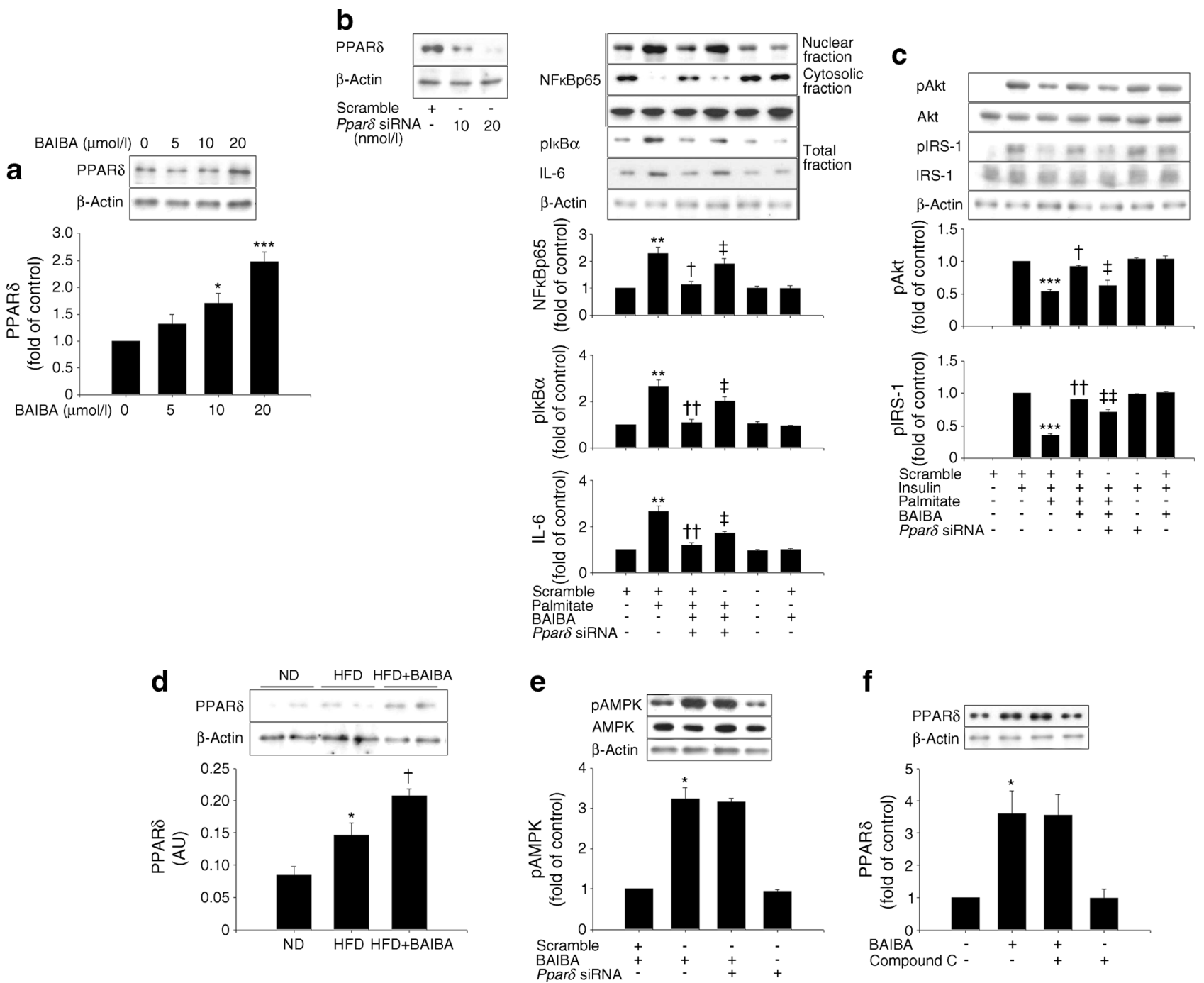

Fig. 5 BAIBA attenuates inflammation and insulin resistance through a PPAR $\delta$-mediated pathway. (a) Western blot analysis of PPAR $\delta$ protein in C2C12 cells treated with BAIBA $(0-20 \mu \mathrm{mol} / 1)$ for 5 days. (b) Verification of Ppar $\delta$ siRNA efficiency in C2C12 cells. Ppar $\delta$ siRNA-transfected $\mathrm{C} 2 \mathrm{C} 12$ cells were treated with BAIBA $(20 \mu \mathrm{mol} / \mathrm{l})$, and palmitate-induced levels of inflammation markers were determined by western blot analysis. (c) Ppard siRNA-transfected $\mathrm{C} 2 \mathrm{C} 12$ cells were treated with BAIBA for 5 days and palmitate for $24 \mathrm{~h}$, and Akt and IRS-1 phosphorylation were determined by western blot analysis. (d) Western blot analysis of PPAR $\delta$ expression in soleus skeletal muscle of mice treated with

HFD and BAIBA (seven animals per treatment group). (e) Ppar $\delta$ siRNAtransfected $\mathrm{C} 2 \mathrm{C} 12$ cells were treated with BAIBA $(20 \mu \mathrm{mol} / 1)$ for 5 days, and AMPK phosphorylation was determined by western blot analysis. (f) $\mathrm{C} 2 \mathrm{C} 12$ cells were treated with BAIBA and compound C $(20 \mu \mathrm{mol} / 1$, $16 \mathrm{~h}$ ), and PPAR $\delta$ expression was determined by western blot analysis. Data are presented as the mean \pm SEM of three separate experiments. ${ }^{* * *} p<0.001, * * p<0.01$ and ${ }^{*} p<0.05$ when compared with the control or the ND. ${ }^{\dagger \dagger} p<0.01$ and ${ }^{\dagger} p<0.05$ when compared with the palmitate or the HFD treatment. ${ }^{\star} p<0.01$ and ${ }^{\star} p<0.05$ when compared with the palmitate plus BAIBA treatment or the HFD plus BAIBA treatment

\section{Discussion}

Exercise is known to be an effective intervention for the treatment of insulin resistance and type 2 diabetes [1]. During exercise, secretion of BAIBA from skeletal muscle to the blood is enhanced through activation of PGC1 $\alpha$ [3]. BAIBA can convert white adipose tissue to brown adipose tissue, which plays beneficial roles in the regulation of glucose metabolism and insulin sensitivity [3, 23]. Moreover, plasma BAIBA levels are inversely associated with metabolic risk

variables and are increased with exercise [3]. Therefore, Roberts et al suggested that BAIBA may contribute to exerciseinduced protection from metabolic disease [3]. However, the mechanisms by which BAIBA may improve insulin resistance in skeletal muscle remain unknown.

AMPK is the master regulator of energy homeostasis and has been reported to inhibit inflammation through inhibition of NFKB signalling [24]. AMPK plays a pivotal role in metabolic diseases such as obesity and type 2 diabetes. Obesityinduced increases in serum NEFA concentration can suppress 

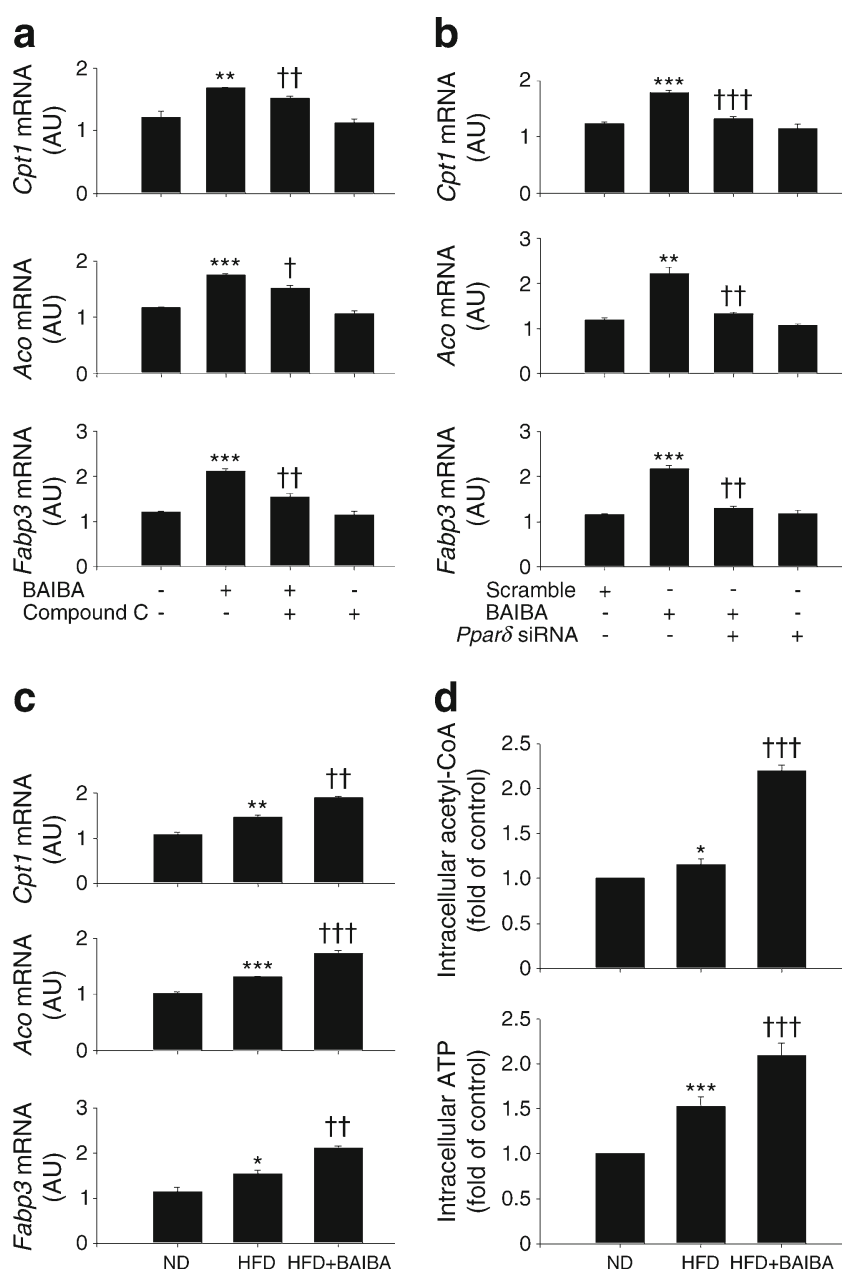

Fig. 6 BAIBA augments $\beta$-oxidation-mediated gene expression. (a) $\mathrm{C} 2 \mathrm{C} 12$ cells were treated with BAIBA $(20 \mu \mathrm{mol} / 1)$ and compound $\mathrm{C}$ (20 $\mu \mathrm{mol} / 1)$. (b) Ppar $\delta$ siRNA-transfected C2C12 cells were treated with BAIBA $(20 \mu \mathrm{mol} / 1)$ for 5 days. Cpt 1 , Aco and Fabp3 mRNA expression was determined by quantitative real-time PCR analysis. (c) Quantitative real-time PCR analysis of Cpt1, Aco and Fabp3 mRNA expression. (d) Intracellular acetyl-CoA and ATP levels in soleus skeletal muscle of mice treated with HFD and BAIBA (150 $\mathrm{mg} \mathrm{kg}^{-1}$ day $^{-1}$ ) for 8 weeks (seven animals per treatment group). Data are presented as the mean \pm SEM of three separate experiments. $* * * p<0.001, * * p<0.01$ and $* p<0.05$ when compared with the control or ND treatment. ${ }^{\dagger \dagger} p<0.001,{ }^{\dagger \dagger} p<0.01$ and ${ }^{\dagger} p<0.05$ when compared with the BAIBA treatment or HFD treatment

AMPK activity [25] and impair insulin signalling [26]. High blood glucose levels in patients with type 2 diabetes also induce oxidative stress and activate NF $\kappa$ B. Conversely, AMPK activation can suppress reactive oxygen species production [27] and can augment the expression of thioredoxin, an inhibitor of the inflammatory response [28, 29]. Increased AMPK activity also attenuates endoplasmic reticulum stress, which results in inhibition of inflammation [30,31]. AMPK is activated in the muscle of patients with type 2 diabetes during exercise [32]. The present study showed that BAIBA significantly induces AMPK phosphorylation. Furthermore, suppression of AMPK abrogated the suppressive effects of BAIBA on inflammation and insulin resistance. These results reveal one possible mechanism through which the beneficial effects of exercise may be mediated through BAIBA.

PPAR $\delta$ has emerged as an important metabolic regulator that may mediate the favourable effects of exercise in diverse tissues, such as fat, skeletal muscle, liver and heart. PPAR $\delta$ receptor activation by a ligand mitigates the macrophagemediated inflammatory response and regulates lipoprotein metabolism to decrease triacylglycerol and increase HDLcholesterol levels. Furthermore, PPAR $\delta$ activation in the liver suppresses hepatic glucose output, leading to attenuation of hyperglycaemia and amelioration of lipopolysaccharideinduced inflammation through inhibition of NFKB activity and TNF- $\alpha$ expression in cardiomyocytes [14]. Fatty acid oxidation and energy dissipation in skeletal muscle and adipose tissue by PPAR $\delta$ activation exerts many beneficial effects, including reducing body weight, increasing skeletal muscle metabolic rate and exercise endurance, improving insulin sensitivity and lipid profiles and suppressing atherogenic inflammation [33]. Therefore, PPAR $\delta$ is an exciting new target for the treatment of the metabolic syndrome [33]. The present study is the first to show that BAIBA treatment can increase the expression of PPAR $\delta$, resulting in alleviation of inflammation through suppression of the NFKB pathway and reduction of proinflammatory cytokines.

By administration of BAIBA to palmitate-treated myocytes, we demonstrated that BAIBA-induced activation of AMPK and PPAR $\delta$ was responsible for a reduction in inflammation. Previous studies have shown that NEFAs can induce inflammation via NFKB activation and upregulation of additional mediators, such as TNF- $\alpha$ and IL-6 [34, 35]. Consistent with previous reports, the present study confirmed that palmitate increased I $\kappa \mathrm{B} \alpha$ phosphorylation, NF $\kappa B$ nuclear translocation and IL- 6 expression, which together result in impaired insulin-stimulated IRS-1 and Akt phosphorylation in $\mathrm{C} 2 \mathrm{C} 12$ myocytes. Furthermore, suppression of both AMPK and PPAR $\delta$ significantly abrogated the suppressive effects of BAIBA on palmitate-induced inflammation, suggesting that induction of AMPK and PPAR $\delta$ by BAIBA contributes to the attenuation of palmitate-induced inflammation. In agreement with the changes in inflammation markers, BAIBA attenuated palmitate-induced elevation of insulin-stimulated IRS-1 and Akt phosphorylation. In vivo experiments using HFD-fed mice also yielded similar results in that BAIBA inhibited the NFKB pathway and the downstream proinflammatory cytokines, such as TNF- $\alpha$ and MCP-1. Overall, these findings suggest that BAIBA alleviates insulin resistance induced by palmitate or an HFD through attenuation of inflammation via an AMPK-PPAR $\delta$-dependent pathway in skeletal muscle. Furthermore, BAIBA improved glucose tolerance and insulin tolerance in mice. In this study, elevated basal glucose levels were detected in experimental mice by performing IPGTTs and ITTs after hyperglycaemia developed as a result of an HFD. Owing to a difference in basal plasma glucose levels, 
a graph of percentage of basal glycaemia was used to estimate insulin sensitivity in the present study. Furthermore, our study showed that HFD-induced basal plasma glucose levels were suppressed by BAIBA administration. This suppressive effect of BAIBA on basal serum glucose levels may be associated with hepatic gluconeogenesis regulated by PPAR $\delta$ [17] or other pathways.

Interestingly, BAIBA administration decreased the body weight of experimental mice, although it did not affect energy intake. These results suggest that loss of body weight is not due to a change in energy intake, but internal mechanisms including fat burning by fatty acid oxidation. Begriche et al indicated no change in body weight but decrease in fat mass by BAIBA treatment in $o b / o b$ mice [2]. This discrepancy may be due to differences in study protocol and experimental animal models.

In agreement with the findings reported by Roberts et al demonstrating that BAIBA induces hepatic fatty acid oxidation through a PPAR $\alpha$-dependent pathway [3], we also confirmed the role of BAIBA-induced $\beta$-oxidation in mouse skeletal muscle cells. Interestingly, the expression levels of PPAR $\delta$ and $\beta$-oxidationassociated genes were increased in the skeletal muscle of HFD-fed mice in the present study. Although the reason for this result is not clear, differences in the stimuli might be involved. This increase in PPAR $\delta$ expression might be mediated by other HFD-induced molecules. Furthermore, the induction of PPAR $\delta$ by the HFD may play a role in the compensatory effects needed to maintain lipid homeostasis. The mechanism of PPAR $\delta$ regulation by an HFD will need to be elucidated in future studies. However, in agreement with our current in vitro experiments, BAIBA administration actively upregulated AMPK phosphorylation and PPAR $\delta$ expression levels in skeletal muscle of HFD-fed mice.

In summary, the present study is the first to demonstrate that BAIBA attenuates insulin resistance and inflammation induced by palmitate or an HFD through a pathway mediated by AMPK-PPAR $\delta$ in skeletal muscle. These results may provide insight into the novel mechanisms contributing to the beneficial effects of exercise and may suggest a therapeutic approach to insulin resistance and type 2 diabetes.

Funding This study was supported by a grant from the Korean Health Technology R\&D Project, Ministry of Health \& Welfare, Republic of Korea (HI14C0133).

Duality of interest The authors declare that there is no duality of interest associated with this manuscript.

Contribution statement TWJ, HJH, HCH, HJY, SHB and KMC provided a substantial contribution to the conception and design of the article, and drafted or revised the article. TWJ and KMC were involved in the acquisition of data and the analysis and interpretation of data. All authors approved the final version of the manuscript. TWJ and KMC are responsible for the integrity of the work as a whole.

\section{References}

1. Bogardus C, Ravussin E, Robbins DC, Wolfe RR, Horton ES, Sims EA (1984) Effects of physical training and diet therapy on carbohydrate metabolism in patients with glucose intolerance and noninsulin-dependent diabetes mellitus. Diabetes 33:311-318

2. Begriche K, Massart J, Abbey-Toby A, Igoudjil A, Letteron P, Fromenty B (2008) Beta-aminoisobutyric acid prevents dietinduced obesity in mice with partial leptin deficiency. Obesity (Silver Spring) 16:2053-2067

3. Roberts LD, Bostrom P, O'Sullivan JF et al (2014) betaAminoisobutyric acid induces browning of white fat and hepatic beta-oxidation and is inversely correlated with cardiometabolic risk factors. Cell Metab 19:96-108

4. Boden G (1997) Role of fatty acids in the pathogenesis of insulin resistance and NIDDM. Diabetes 46:3-10

5. Vessby B, Uusitupa M, Hermansen K et al (2001) Substituting dietary saturated for monounsaturated fat impairs insulin sensitivity in healthy men and women: the KANWU Study. Diabetologia 44:312-319

6. Coll T, Eyre E, Rodriguez-Calvo R et al (2008) Oleate reverses palmitate-induced insulin resistance and inflammation in skeletal muscle cells. J Biol Chem 283:11107-11116

7. Senn JJ (2006) Toll-like receptor-2 is essential for the development of palmitate-induced insulin resistance in myotubes. J Biol Chem 281:26865-26875

8. Kim JK, Kim YJ, Fillmore JJ et al (2001) Prevention of fat-induced insulin resistance by salicylate. J Clin Invest 108:437-446

9. Kern PA, Ranganathan S, Li C, Wood L, Ranganathan G (2001) Adipose tissue tumor necrosis factor and interleukin-6 expression in human obesity and insulin resistance. Am J Physiol Endocrinol Metab 280:E745-E751

10. Pickup JC, Mattock MB, Chusney GD, Burt D (1997) NIDDM as a disease of the innate immune system: association of acute-phase reactants and interleukin-6 with metabolic syndrome $X$. Diabetologia 40:1286-1292

11. Zhang BB, Zhou G, Li C (2009) AMPK: an emerging drug target for diabetes and the metabolic syndrome. Cell Metab 9:407-416

12. Shoelson SE, Lee J, Goldfine AB (2006) Inflammation and insulin resistance. J Clin Invest 116:1793-1801

13. Narkar VA, Downes M, Yu RT et al (2008) AMPK and PPARdelta agonists are exercise mimetics. Cell 134:405-415

14. Ding G, Cheng L, Qin Q, Frontin S, Yang Q (2006) PPARdelta modulates lipopolysaccharide-induced TNFalpha inflammation signaling in cultured cardiomyocytes. J Mol Cell Cardiol 40:821-828

15. Kilgore KS, Billin AN (2008) PPARbeta/delta ligands as modulators of the inflammatory response. Curr Opin Investig Drugs 9:463-469

16. Lee $\mathrm{CH}$, Chawla A, Urbiztondo $\mathrm{N}$ et al (2003) Transcriptional repression of atherogenic inflammation: modulation by PPARdelta. Science 302:453-457

17. Lee CH, Olson P, Hevener A et al (2006) PPARdelta regulates glucose metabolism and insulin sensitivity. Proc Natl Acad Sci U S A 103:3444-3449

18. Odegaard JI, Ricardo-Gonzalez RR, Red Eagle A et al (2008) Alternative M2 activation of Kupffer cells by PPARdelta ameliorates obesity-induced insulin resistance. Cell Metab 7:496-507 
19. Barish GD, Narkar VA, Evans RM (2006) PPAR delta: a dagger in the heart of the metabolic syndrome. J Clin Invest 116:590-597

20. Koves TR, Ussher JR, Noland RC et al (2008) Mitochondrial overload and incomplete fatty acid oxidation contribute to skeletal muscle insulin resistance. Cell Metab 7:45-56

21. Lee WJ, Kim M, Park HS et al (2006) AMPK activation increases fatty acid oxidation in skeletal muscle by activating PPARalpha and PGC-1. Biochem Biophys Res Commun 340:291-295

22. Tanaka T, Yamamoto J, Iwasaki S et al (2003) Activation of peroxisome proliferator-activated receptor delta induces fatty acid betaoxidation in skeletal muscle and attenuates metabolic syndrome. Proc Natl Acad Sci U S A 100:15924-15929

23. Stanford KI, Middelbeek RJ, Townsend KL et al (2013) Brown adipose tissue regulates glucose homeostasis and insulin sensitivity. J Clin Invest 123:215-223

24. Salminen A, Hyttinen JM, Kaarniranta K (2011) AMP-activated protein kinase inhibits NF-kappaB signaling and inflammation: impact on healthspan and lifespan. J Mol Med (Berl) 89:667-676

25. Wu Y, Song P, Xu J, Zhang M, Zou MH (2007) Activation of protein phosphatase $2 \mathrm{~A}$ by palmitate inhibits AMP-activated protein kinase. J Biol Chem 282:9777-9788

26. Boden G (1999) Free fatty acids, insulin resistance, and type 2 diabetes mellitus. Proc Assoc Am Physicians 111:241-248

27. Wang S, Zhang M, Liang B et al (2010) AMPKalpha2 deletion causes aberrant expression and activation of NAD(P)H oxidase and consequent endothelial dysfunction in vivo: role of $26 \mathrm{~S}$ proteasomes. Circ Res 106:1117-1128
28. Zhou R, Tardivel A, Thorens B, Choi I, Tschopp J (2010) Thioredoxin-interacting protein links oxidative stress to inflammasome activation. Nat Immunol 11:136-140

29. Li XN, Song J, Zhang L et al (2009) Activation of the AMPKFOXO3 pathway reduces fatty acid-induced increase in intracellular reactive oxygen species by upregulating thioredoxin. Diabetes 58:2246-2257

30. Dong $\mathrm{Y}$, Zhang $\mathrm{M}$, Wang $\mathrm{S}$ et al (2010) Activation of AMP-activated protein kinase inhibits oxidized LDLtriggered endoplasmic reticulum stress in vivo. Diabetes 59:1386-1396

31. Terai K, Hiramoto Y, Masaki M et al (2005) AMP-activated protein kinase protects cardiomyocytes against hypoxic injury through attenuation of endoplasmic reticulum stress. Mol Cell Biol 25:9554-9575

32. Musi N, Fujii N, Hirshman MF et al (2001) AMP-activated protein kinase (AMPK) is activated in muscle of subjects with type 2 diabetes during exercise. Diabetes 50:921-927

33. Reilly SM, Lee CH (2008) PPAR delta as a therapeutic target in metabolic disease. FEBS Lett 582:26-31

34. Tripathy D, Mohanty P, Dhindsa S et al (2003) Elevation of free fatty acids induces inflammation and impairs vascular reactivity in healthy subjects. Diabetes 52:2882-2887

35. Chavez-Tapia NC, Rosso N, Uribe M, Bojalil R, Tiribelli C (2013) Kinetics of the inflammatory response induced by free fatty acid accumulation in hepatocytes. Ann Hepatol 13:113-120 